\title{
LEARNING ONE'S PLACE AND POSITION THROUGH PLAY: SOCIAL CLASS AND EDUCATIONAL OPPORTUNTIY IN EARLY YEARS EDUCATION (EYE)
}

\author{
By JULIE STIRRUP and JOHN EVANS Loughborough University
}

\begin{abstract}
This paper focuses on how learning is structured and organised through play in three Early Years Education settings in England, UK. Drawing on the theoretical work of the British sociologist Basil Bernstein and with reference to the structure and organisation of learning, it is argued that the multiple forms of play evident in the three settings are afforded very different status and value in each, influenced by the assumptions practitioners make about children and their families' knowledge and resources for learning. The effect of such processes is the reproduction, rather than erosion, of social hierarchies inside EYE settings, reflecting those longstanding in wider UK society.
\end{abstract}

Keywords: Early Years Education, social class, play, pedagogy

\section{INTRODUCTION}

Building on Rogers and Lapping's (2012) Bernsteinian inspired research (reported in this journal) on the discursive reconstruction of play within Early Years Education (EYE) policy in the UK, this paper aims to further illuminate 'play' as a cultural practice, recontextualised through its organisation, structure and transmission in EYE settings. Historically, the UK has had a legacy of uneven, underfunded provision for young children and their families; however, since 1997 there has been a continual political shift to enhance early year's policy through several reforms. Successive New Labour governments enacted a number of policy initiatives, including Sure Start (DfE, 1998), Birth to Three Matters (DfE, 2002) and The Early Years Foundation Stage (EYFS, 2008) all focusing on the education of children aged 05. The current Conservative led government has similarly shown its commitment to early years education, endorsing a revised EYFS (2014) (the guiding document for practice in the early years in England) and affirming the principle that each child is unique, developing in different ways and should be encouraged to learn through positive relationships, in an enabling environment (EYFS 2014).

UK policy discourse around early childhood education has historically (i.e., since Plowden, 1967) drawn on developmental psychology, in particular Vygotsky (1978) to emphasis learning through play. Acknowledging the vast amount of literature claiming the benefits of play based, developmentally sensitive pedagogies within the early years (see Wood and Altfield, 2005; Siraj-Blatchford and Sylva, 2004) successive governments in England (and indeed many countries elsewhere, see Bertram and Pascal, 2002) have retained a play based, individually tailored approach to teaching and learning in the early years Notwithstanding some subtle but significant discursive shifts in the 'official' purpose of EYE play, toward more instrumental, performative goals (Rogers and Lapping, 2012), the EYFS (2014) advocates viewing a child as an individual whose learning needs must be met essentially through play, which may be both child and adult initiated: 
Children learn by leading their own play, and by taking part in play which is guided by adults...Practitioners must respond to each child's emerging needs and interests, guiding their development through warm, positive interaction (EYFS, 2014: 9).

In EYE discourse then, play is the primary pedagogical mode through which learning takes place, however, how play and, therefore, learning is organised, is not specified in EYFS literature. Early years research (e.g. Siraj-Blatchford and Sylva, 2004; Bodrova and Leong, 2007) has strongly suggested that most EYE providers believe that play is undeniably an important element of early years learning, 'virtually all early childhood educators...espouse play as a sacred right of childhood... as the way in which young human beings learn' (Viruru, 1997:124). If, then, we accept received orthodoxy around the importance of play in EYE, it follows that the ways in which practitioners organise and structure play activity including the amount of time and resource they allocate to it, must in itself be considered a 'message system' potentially of great importance in the lives of children. Historically there has been heated theoretical argument around the merits of play pedagogy and its contribution to learning and development (see McNaughton, 2005). However, this paper does not focus on what play is, or whether it should be more or less structured, but rather on how play is recontextiualised, i.e., interpreted and enacted by practitioners when mediated by their perceptions of children's social class and culture.

\section{THEORISING PLAY}

Play as pedagogy is not straightforward (Wood 2007; Walsh et al 2010) and in recent years much debate has revolved around its role within EYE. There is now a good deal of consensus however, that high quality EY pedagogy is a balance between child and adult initiated play and a mixture of pedagogies to suit the content (Mellhuish et al, 2004; Siraji- Blatchford, et al 2002).

To explore and advance our understandings of play and its relationship to social class and culture we, like Rogers and Lapping (2012) look to the seminal work of Basil Bernstein (1973) on education in the early years to inform our analyses. In particular we use his concepts 'visible and invisible pedagogies', 'classification and frame' , 'instructional' and 'regulative' discourse, to describe and illuminate how the structuring and organisation of 'play' reflect, express and affect the relations between home, family and culture and the transactions that materialise inside early years settings.

Bernstein (1973) sought to articulate the class and cultural origins and implications of a form of pedagogy which he termed 'invisible' and which post Plowden (1967) was beginning to feature as the dominant pedagogy for children in the early years in the UK and elsewhere. This pedagogy featured play as the primary medium through which a child is expected to express her/himself to practitioners and through which they learn social, emotional and cognitive skills. Bernstein (1975) characterised 'invisible pedagogy' as a pedagogy in which practitioners' control over children is implicit (for example, practitioners set out activities but do not tell the children what activity to do) and children have considerable control over the selection, pacing and timing of knowledge acquisition, as well as their own movements and social relationships. Consequently, the criteria for knowledge transmission is realised through 
interpersonal forms of communication and control. Within this form of pedagogy, the child demonstrates his/her ability and potential to the practitioner through their manifest engagement in play. The concepts 'busy', 'ready' and 'doing' thus become critical elements in the assessment of learning and learners. Some forms of play are more productive than others, some involve individual rather than social play (Bernstein 1975) and each form allows practitioners to evaluate and assess children's progress and potential.

In EYE discourse, play is often used to describe everything a child does and whilst there are potential pitfalls to over using the term (see Duffy, 2014), the complexity of play as a concept does lead us to ask, how do children learn to 'play appropriately' and know which forms of play are valued and therefore which form they should display most (see MacClure et al, 2011). Research has highlighted how practitioners' meanings of play differ and specifically how they often associate 'good' play with clear learning objectives (Brooker, 2010).

Bernstein argued that children's play in EYE is never value free but rather linked fundamentally to culture and class. Different communities and cultures value different forms of play and invoke different strength boundaries ('classifications') between and control over ('frame’) ‘work' and play. For example, Bernstein (1975) (using rather over generalised terms) suggested that for 'the working class', work and play are strongly bounded and framed, whilst for the 'new middle class' there is weak classification and frame between work and play; 'play is work and work is play' (Bernstein, 1977, p.24) there is no obvious boundary between the two. Play work for the middle classes he argued, carries 'intrinsic' satisfactions (inner pleasure and outer prestige) and therefore is not confined to one context; whereas for the working class, work and play are strongly separated and situationally specific.

Although Bernstein's conceptualization of class now seems rather over generalised and dated (given the social structural changes to have occurred since the 70's in the UK), such characterisations were only ever intended as heuristic devices to be used judiciously, as they are here, in empirical analyses of play in EYE. With this in mind we now turn to the contexts of play as experienced in the three EYE contexts of this study in order to explore these ideas in greater detail.

\section{METHODOLOGY}

This research was set within three publically (Government) funded but socially and culturally different early years settings in central England: Busy Buzzy Bees (BBB), LP (LP) and LS (LS) (pseudonyms, see table 1).

Busy Buzzy Bees is located in a large midlands town. It provides sixty childcare places for children aged three months to four years old (although only the three and four years old were the focus of this research) and is commonly utilised by staff and students at the local college. Housed in three mobile classroom units, the setting consists of one unit, divided into four separate sections; one for each age group (ages three months -one year , two-three years and three-four years), with each 'section' catering for up to fifteen children supervised by two or three practitioners at any one time. The other two units were mostly used as office space. The outdoor facilities consist of a large playground which each group uses at different times 
of the day. As many of its children are from professional middle class families it provided stark contrast to the working class families who use ' $L P$ ' and ' $L S$ '.

Little People is located within a large housing estate on the outskirts of a large town in the middle of England. It serves the local community, providing childcare for children aged three to four years old. The setting has two rooms dedicated to three-four year olds - one for children whose parents paid for their full time care and, the other for those who only attended for their entitlement of fifteen hours Government funded 'free care' per week. It was the latter room on which this research focussed and at any one time it catered for twenty five children supervised by three to four practitioners. The building itself consists of one large classroom for indoor play and a large outdoor area with climbing frame, soft play area and 'garden'.

Little Stars is a preschool located within a market town in the midlands catering for a number of ethnic groups (mainly Bangladeshi families) within the community. This setting was selected because of its cultural diversity. Approximately eighty per cent of the children on roll were from ethnic minorities and of that forty-five per cent spoke English as an additional language. It operated out of three large rooms within one building, offering two daily three hour childcare sessions for three-four year olds, catering for up to forty children at any one time, supervised by four - five practitioners.

Table 1: An overview of the demographic profile of each setting

\begin{tabular}{|l|l|l|l|}
\hline & BBB & LP & LS \\
\hline Age of children & 3-4years & 3-4years & 3-4years \\
\hline $\begin{array}{l}\text { Social Class } \\
\text { those who use the } \\
\text { settings }\end{array}$ & $\begin{array}{l}\text { Working (employed) } \\
\text { Middle Class parents }\end{array}$ & $\begin{array}{l}\text { Mostly unemployed } \\
\text { Working Class } \\
\text { parents }\end{array}$ & $\begin{array}{l}\text { Working class and } \\
\text { multicultural parents }\end{array}$ \\
\hline $\begin{array}{l}\text { SES score } \\
\text { ii }\end{array}$ & 18112 & 8521 & 1180 \\
\hline $\begin{array}{l}\text { SES Score educational } \\
\text { attainment }\end{array}$ & 28597 & 3628 & 7556 \\
\hline $\begin{array}{l}\text { Government } \\
\text { Funded } \\
\text { 4year olds) }\end{array}$ & Yes & Yes & Yes \\
\hline
\end{tabular}

The research involved ten months of sustained 'critical' ethnographic fieldwork in the three settings, with the researcher using participant and non-participant observation, field notes and informal conversations with children and practitioners to gather data. Across the three settings, eighty children and fifteen practitioners were observed. The data collected were first 
analysed ethnographically to determine the practitioners' organising categories and concepts of the setting. Second order analysis imposed the researcher's sociological frame of reference in questions of equity and social reproduction, thereby adding another layer of analysis to the study. The third level explored transactions at a micro level through case studies, detailing interactions between staff/children and children/children, all contextualised within time, space and place to provide insight into the social hierarchies of each setting and the opportunities children had to participate in each form of play. The categories of play (academic, physical, practitioner led physical, spontaneous and work play; see figure 1) identified below were the inductive constructions of the researcher, albeit grounded in eighty hours of observation. How these various play forms were realised in each setting and the consequences of this process for children's learning opportunities and identities are addressed below.

\section{EYFS POLICY: DISCURSIVELY SETTING THE SCENE}

As policy, the EYFS (2014) has to be considered a 'discursive embodiment' (Olssen, Codd and O'Neill, 2004) of the social and political dynamics of current education policy dominated by neoliberal principles of choice and performativity (Ball, 2003; 2010; Rogers and Lapping, 2012). As Rogers and Lapping (2012) argue, the Rumbold Report (1990) (which reported on 'the quality of the educational experience offered to 3 and 4 year olds' in the UK) foreshadowed a shift from the progressive child centred ideology of the post Plowden era to a market driven ideology of accountability for education and play. This is evident in EYFS (2014) policy which emphasises principles of accountability and managed choice, with phrases such as 'well planned', 'challenging play' and 'planned purposeful', suggesting that some forms of play are more valued than others and that a narrow 'school readiness' agenda dominates at the expense of other more expressive play forms.

In order to make children 'school ready' the EYFS (2014) identifies three characteristics of effective teaching and learning;

- Playing and exploring - children investigate and experience things, and 'have a go';

- Active learning - children concentrate and keep on trying if they encounter difficulties, and enjoy achievements; and

- Creating and thinking critically - children have and develop their own ideas, make links between ideas, and develop strategies for doing things (DfE, 2014: 9).

These characteristics are ideally realised through a curriculum defined by different forms of play enacted within each setting. Therefore, the ways practitioners' respond to each child is, as Bernstein attests, likely to be influenced by their subjective view of children's 
predispositions, potential achievement and 'readiness' to meet the expectations of the EYFS. EYFS criteria stipulate what children should achieve during their time at nursery, with progression assessed through practitioner observations (EYFS, 2014). What then must children do and display in order to be seen as developing 'appropriately' i.e., in keeping with the EYFS 'ideal' imaginary child? The EYFS (2014) sets out a model for the 'imaginary learner' through seventeen 'early learning goals' (ELGs). Together they establish specific ideals of the stages of development a child should reach at various ages. Implicitly then, within the EYFS is an assessment process of disciplinary power that defines some children as 'normal' and others as 'failing' (McNaughton, 2005; Maclure et al, 2011) or in the words of EYFS 'emerging'. As table 2 highlights, by age 3 or 4, it 'expects' children to achieve a certain level of development which for some may be unrealistic for various reasons (biological, physical or social, etc.). Taking Bernstein's view, two aspects of a child have to be visible to the practitioner for this evaluation of learning and progress to occur. The first, 'readiness', arises out of a practitioner's assumptions of a child's behaviour and stage of development. The second aspect, 'busyness', refers to the child's outer behaviour which practitioners interpret as evidence of a child's inner readiness. In other words, a child's inner readiness is expressed as outer busyness.

\section{Class and the Pedagogies of Play}

Within each of the three settings, children acquire and construct knowledge -skills, values and behaviours differently, depending on the structure, organisation and time allocated to different forms of play. Children arrive at their nursery already functioning members of their own social worlds and in some case have to relearn how to 'perform' as a successful member (recognising the behaviour, rules, and expectations) of their early years setting. In the process some children's (and parents') expectations may be interrupted in the dislocation of values between home and school. Previous research (e.g. Bradbury, 2013; Ball, 2010) has highlighted how social class impacts children's learner identities within formal school settings. As Ball (2010) argues, middle class children whose parents invest in 'edutainment' are advantaged when they arrive at (pre) school:

Enrolling under-5s in activities of these kinds ensures children develop a complex set of physical, social and intellectual skills and embodiments which eave them in a state of 'learning readiness', prepared form future success at school’ (Ball, 2010:161)

In each of the three settings practitioners distributed knowledge and evaluated children's development in relation to what they were expected to bring to the setting by way of knowledge and predispositions and to have acquired during their time in the setting. For example, across all three settings, children were expected to know how to share toys (and were instructed how to 'share' if they didn't - i.e., 'regulative discourse') and as their time in the setting progressed, they were also expected to know how to perform certain knowledge skills, e.g., 'count up to ten' ('instructional discourse'). At $B B B$, however, children were perceived to arrive at the setting already predisposed with knowledge of how to do these 
things; sit, listen and share toys, allowing practitioners to focus on the development of their cognitive skills.

Helen (room leader): Many of our parents want us to work on their children's phonetic, but that's not our job, that's for primary school. We try to develop each child and prepare them for school; we do lots of reading and work on our letters. Parents often do a lot of the academic stuff at home as well.

Figure 1: The learning board at $B B B$ on which practitioners placed the 'letter of the week' and asked children to remember words that begin with that letter.

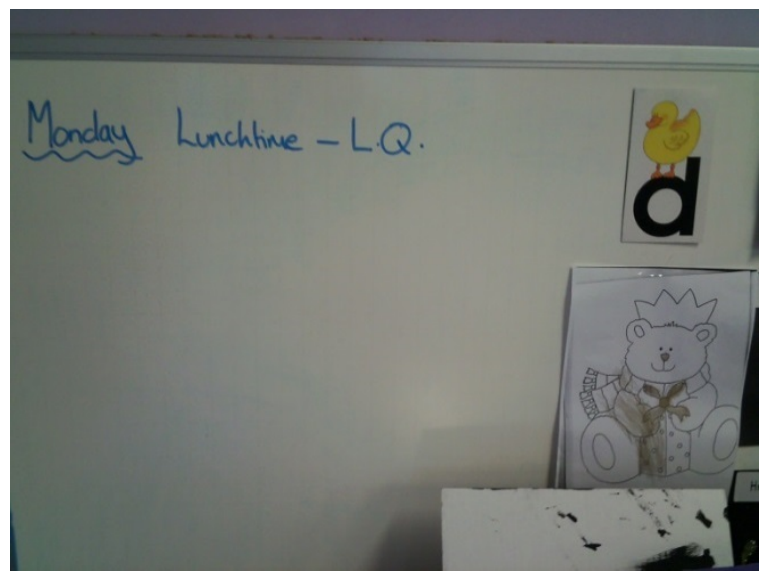

In contrast, at $L P$ and $L S$, practitioners did not expect children to arrive predisposed with such knowledge.

Jane (room leader): We spend a lot of time working on their behaviour - sitting still, playing nicely, sharing etc. For many of our children, this is the only time they get to play in such a large space.

Figures 2 and 3: The large indoor and outdoor spaces at $L P$ in which children spend most of their time playing and running around.
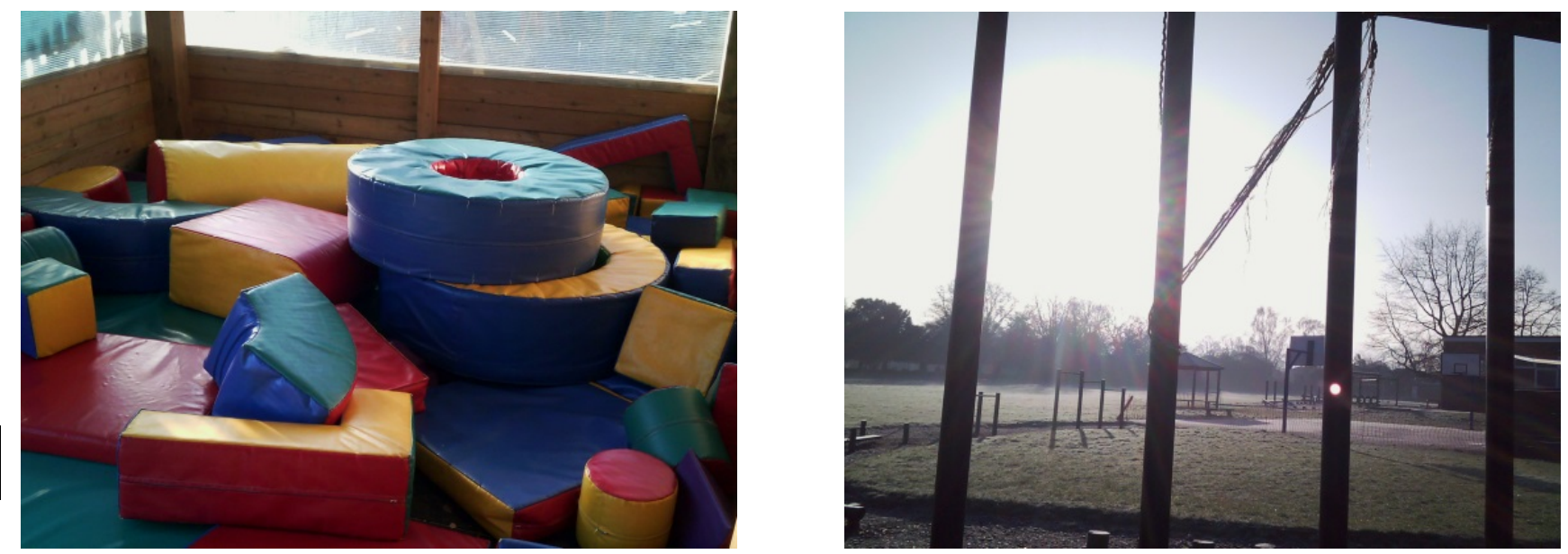
At $L S$, practitioners talked about their focus being on developing children's social skills;

Mrs Robinson (deputy manager): many of our children come from Bangladeshi backgrounds, they have a different culture and for some English is not their first language or the language they speak at home. For us, we focus on the basics, sitting and listening, sharing and playing with others.

Figure 4: The key rules which guide learning at $L S$

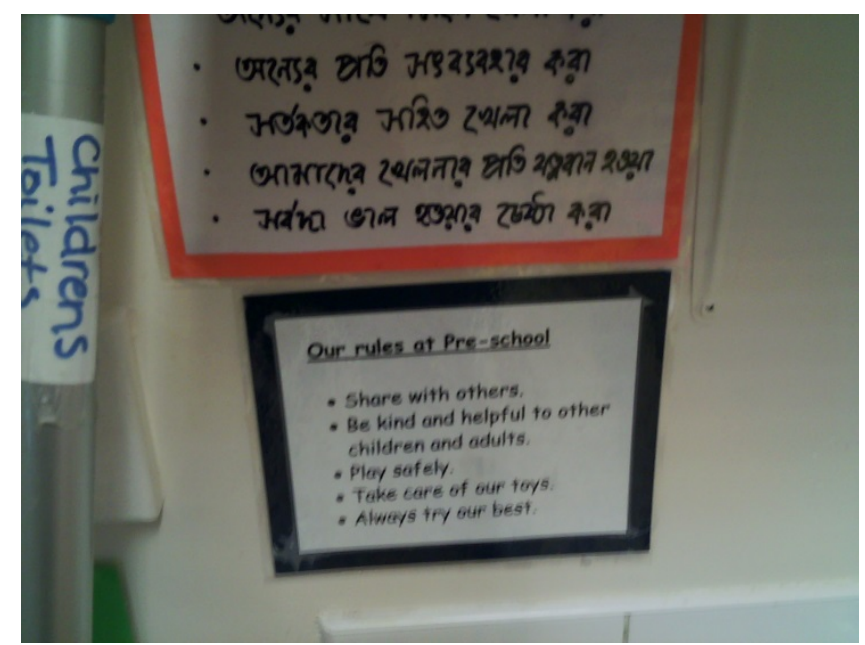

In all three settings, practitioners made evaluative judgements about children's readiness for school, based on not only observations, but also expectations and prior assumptions regarding their social and cultural backgrounds. These assumptions and expectations underscored the structuring of play in each setting, in effect either facilitating or limiting children's opportunities to learn.

\section{THE NATURE OF PLAY PEDAGOGY IN THE EARLY YEARS}

Different forms of play ${ }^{\text {iv }}$ were valued across the three EYE settings (see Table 2). At $B B B$, all forms of play were weakly classified when compared to $L P$ and $L S$ where work and play were strongly classified and framed. That is to say, in these latter settings work play and all other forms of play occurred in two distinct areas- work play in the 'learning room' and all other forms of play in the main room or outside play area (see Table 2). 
Table 2: Play in the early years

\begin{tabular}{|c|c|c|c|c|}
\hline $\begin{array}{c}\text { Work Play } \\
\text { Practitioner } \\
\text { initiated time } \\
\text { dedicated to } \\
\text { learning } \\
\text { numeracy and } \\
\text { literacy skills }\end{array}$ & $\begin{array}{c}\text { Academic Play } \\
\text { Child initiated } \\
\text { involvement in } \\
\text { play focused on } \\
\text { learning skills } \\
\text { e.g. jigsaws, } \\
\text { practicing } \\
\text { writing, reading }\end{array}$ & $\begin{array}{l}\text { Physical Play } \\
\text { Gross motor } \\
\text { movements such } \\
\text { as running, } \\
\text { riding a toy car, } \\
\text { jumping, } \\
\text { dancing or } \\
\text { rough and } \\
\text { tumble play- } \\
\text { child initiated }\end{array}$ & $\begin{array}{l}\text { Spontaneous } \\
\text { Movement } \\
\text { Moving to and } \\
\text { from activities, } \\
\text { between areas to } \\
\text { see what is } \\
\text { going on }\end{array}$ & $\begin{array}{c}\text { Practitioner } \\
\text { Led Physical } \\
\text { Activity } \\
\text { Formal physical } \\
\text { activity e.g. } \\
\text { children learning } \\
\text { different ways to } \\
\text { move. } \\
\text { Something that } \\
\text { has been } \\
\text { planned and is } \\
\text { led by } \\
\text { practitioners }\end{array}$ \\
\hline
\end{tabular}

The five distinct, clearly bounded categories of play recorded over 180 hours of ethnographic observation in each setting.

Although each form of play was present within all three settings, they were differently distributed in relation to time, value, emphasis and meaning attributed to them in each setting. 
Figure 51: Play differences within early years (* Practitioner Led Physical Activity was not a daily activity

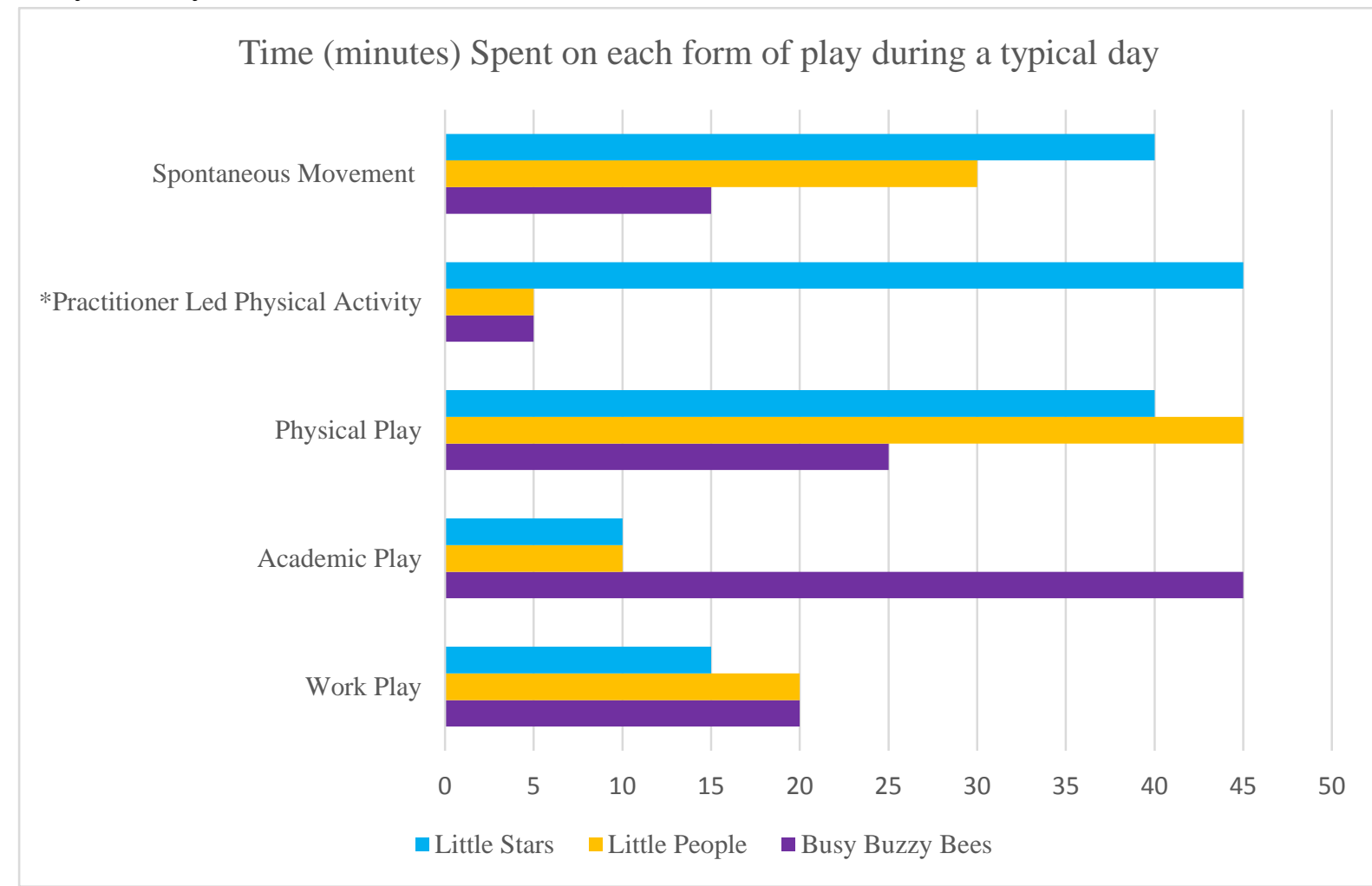

Across all three settings three forms of play, work, academic and physical dominated in as much as they received far more time and practitioner attention than any other play form and for that reason we centre attention on them here. Academic play describes time when children chose to play indoors, often sitting around a table or carpet area playing with construction toys (e.g. Lego/jigsaws) or engaging in role play (e.g. doctors or families) during which time practitioners engaged them in discussion to assess or cultivate their knowledge. Physical play refers to time when children choose to play outdoors with bikes, on climbing frames or engage in games such as 'chases'. Practitioners observed and watched these activities for health and safety reasons but did not participate in conversations with children about their knowledge around physical movement or health. In contrast, work play occurred either at tables or in a specific room and was practitioner led, predominately focused on fulfilling the 'literacy', 'numeracy' and 'understanding the world' aspects of the EYFS (2014: 8). It aimed to help children develop their knowledge in relation to reading and counting etc. and give practitioners the opportunity to assess children's knowledge in a more 'formal' context. Activities observed throughout work play included - counting out food to feed the farm animals (plastic versions) and exploring if certain objects would float or sink. The key features of each context in relation to these forms of play are explored below.

Distributive rules of space, time and discourse during 'Work Play'

Within all three settings learning took place through the aforementioned forms of play and in each there was strong classification of time, space and discourse, during 'work play'. For example, in all three settings, throughout the daily 15/20 minutes 'work play’ sessions, 
discourse was strongly framed in terms of specialised skills and language used by practitioners and expected from the children. At $B B B$ and $L P$, children regularly took part in science 'experiments' learning terms such as 'float, sink, light, heavy'. Furthermore, as the examples below highlight, practitioners controlled the pace of the lesson (work play) through questioning, often aimed at certain children to evaluate learning.

Example 1 'Work Play’ at $B B B$ - field notes

Helen: What do you think might happen if they (kites) are light?

James, Amy and Ian: they’ll fly

Helen: That's right, let me get my air machine, Adam would you like to have a go....do you think yours will fly?

Adam: Yes its light

Helen: Agh....now that didn’t fly did it? Why do you think?

In this example Helen controls both the pacing and sequence of the session, and also the knowledge that is being transmitted within the interaction. However, the space boundaries between work and academic play were weak, with both taking place in the same area and at the same time. Comparable strongly framed episodes were observed at LP and LS, although 'work play' at $L S$, focused more on reading and featured a stronger framing in terms of sequence and selection of knowledge, since the children sit and listen rather than actively take part. Furthermore, at both $L S$ and $L P$, there was a stronger boundary maintenance created by the classroom door, children were made aware that the space was for reading (i.e., work play) with the practitioner and when the door was shut, they were not allowed out or others in. Here there is recognition that 'work play' is a distinctive activity marked out by the space, resources and presence of the practitioner. This was often made evident (i.e., announced symbolically) in $L S$ through the closing of the classroom door. In this setting the realisation rules for children (i.e. how they might acquire the pedagogic code and participate in 'work play') related to adhering to the pacing and sequencing of the session, engaging and displaying some level of attention and knowledge through their answers. During 'work play' then, the pedagogy across all three settings was highly visible, control was maintained through explicit ordering and structuring of time, space and discourse promoting individual child attainment, with progress being recorded in children's 'learning journeys'v . Knowledge during these sessions was strongly classified as school related and both regulative and instructional discourse was strongly framed.

\section{Distributive rules of space, time and discourse during 'Physical and Academic Play'}

'Academic and physical play’ dominated children's time across all three settings, although there were very significant differences in the amount of time spent on each when we compare $B B B$ to $L S$ and $L P$. In both forms of play, space and time were weakly framed, that is to say, children were free to use all the space and were in control of the time they chose to spend on each play form with children working collaboratively at self-chosen activities. Within this 
context, children were expected to self-regulate in the absence of explicit sequencing or tight time boundaries; and control and evaluation occurred through personalised communication focused on intentions, dispositions and relationships. Occasionally practitioners intervened to evaluate the learning taking place through informal conversations and observations.

In contrast to 'work play', there was no obvious (at least to the children) or distinguishing outcome required during ‘academic and physical play’. Recognition rules (e.g., defining appropriate behaviour) were thus difficult to identify and acquire, and not every child was considered ready to do this, particularly those many deemed 'less able' at LP and LS (see authors, 2017). Such children tended to spend most of their time doing 'physical play' which was in stark contrast to $B B B$ where children appeared predisposed and 'able' to recognise that 'academic play' was valued more highly. As mentioned earlier, Bernstein (1975) maintained that within invisible pedagogies, practitioners observe children's 'readiness' (their stage of development) with reference to their 'busyness' (external behaviour) and in this way assess if they demonstrate 'appropriate' competence (realisation rules). 'Busyness' within each of the settings was depicted as a 'good thing'; children being busy meant they had acquired some level of social/situational competence and were able to learn and play in accordance with the practitioners and settings social/cultural perceptions;

Example 1 - 'Busyness' at BBB

At $B B B$, most children choose to engage in 'academic play' regularly, particularly when given the option of doing 'experiments' such as building kites and testing to see if they are light enough to fly. Jane suggests that such 'busy' behaviour is encouraged at home as well.

Jane: "We try to encourage them to do 'experiments' and certainly I think it's good for them, to prepare them for school. But some parents want even more academic focus. They come with so much knowledge already. It's great for us, we can do lots of fun stuff then, such as building those kites and using the air machine to test them”.

Example 2 - 'Busyness’ at $L P$

Sarah (practitioner): It's good to see the children engage in an activity and play with others, most do but one or two just move from activity to activity never really engaging.

Example 3 - 'Busyness’ at $L S$

As Mrs Jones explains, the children are always busy, moving round, rarely sitting still but some are more productive than others.

Mrs Jones: Those boys, they love to play Power Rangers and we can do so much with that, we bring in the theme tune for them to dance to and make posters in art. Others just wander from activity to activity, never really engaging.

In each of these extracts, practitioners made judgements based on what they perceived as acceptable in terms of 'busyness'. However, their judgments are not arbitrary; they are influenced by their individual interpretations of the EYFS and cultural beliefs about how a 
child should behave. At $B B B$, 'acceptable' busy behaviour is that displayed through 'academic play' and the practitioners believed there was no dislocation between the value placed on this form of play at nursery and at home. Similarly, at $L P$ and $L S$ children were viewed as busy if they engaged in 'productive' meaningful play, which for these two settings meant playing at one activity, the type of play was less important. However, across all three settings, busyness was defined by what was visible to practitioners - what they could see a child doing (or not doing). There was, in effect, total and ongoing invisible surveillance and evaluative assessment of children's ability and potential made manifest in each of these play forms.

\section{WHAT COUNTED AS LEARNING: REGULATIVE AND INSTRUCTIONAL DISCOURSE}

Within all three settings, children were required to understand and follow recognition rules, e.g., knowing how and when to behave and demonstrate their skills and knowledge 'appropriately'. In the practitioners' eyes, to become an effective member of the setting children had to actively display and perform social and situational competence. At LP and LS the dominant discourse focused on regulating children's social behaviour. Children were constantly being reminded how to be polite, behave and share with others, and how to sit and listen. At $B B B$ instructional discourse dominated the setting; being and becoming a successful learner meant actively showing you knew how to behave appropriately in the classroom in all forms of play.

Discourse at $L P$ and $L S$

In both these settings, the role of the practitioner (as defined by themselves and the settings expectations) was to educate children both socially and academically ${ }^{\mathrm{vi}}$, however, the former took precedence. In the practitioners' view - 'we need them to behave appropriately and have kind hands before we can work on their counting' (Jane, $L P$ ) hence little time being spent on 'work or academic play' in either setting (see Figure 1). Visibly displaying listening skills was therefore critically important in relation to a child demonstrating competence. However, in both contexts the rationale for developing listening skills had more to do with social control (regulating immediate behaviour) than with (projected) school readiness, as highlighted in Ms Smith's comment to a group of boys who were rolling around on the floor during 'song time';

Example 1- regulative discourse at $L S$

Ms Smith: Boys! You must sit and listen while we sing our song....everyone else is sat nicely. You are being very silly; this is not how we behave at preschool.

The relative paucity of instructional discourse in both these settings was evident within several transactions between practitioners and children. However, regulative discourse was not evenly distributed amongst the children in these two settings, as it was adjudged that some needed more of it than did others. For example, practitioners across both settings regularly spoke to the same children about their poor behaviour and identified the same children to sit next to during 'gathering' and group work, to ensure they listened and sat as 
expected. These children had previously and repeatedly failed to demonstrate the correct behaviour and consequently they received more practitioner attention.

Whilst regulative discourse was evident within $B B B$, instructional discourse dominated the setting and there was a strong emphasis on 'specialised' knowledge construction in child/practitioner and child/child interactions (see example 1 below). It was evident that children largely shared and brought with them from home the same behavioural expectations as those valued in nursery. As such, regulative discourse when used at $B B B$, reached out to a wider context, emphasising the need to make children in this setting school ready. For example, children were required to be aware of the importance of listening 'quietly and attentively' during registration and displaying what practitioners deemed 'school appropriate' manners. Even when using regulative discourse, practitioners made sure there was also a 'school' purpose.

Example 1 - Regulative discourse at $B B B$

Laura: Right, James and Tom tell everyone why it's important to listen at register time...

Tom: we have to make sure everybody's inside

James: and we don’t left anybody outside

Laura: we don't leave anybody outside, so I just ask that you listen for TWO minutes ok and then I can do it quick. It's very important and when you go to school you do a register at school as well, so you have to get used to doing it and it takes longer at school because there is more children.

Furthermore, children at $B B B$ were encouraged to bring toys etc. from home into nursery and participate in 'show and tell', giving children a sense that their home experiences were valued within nursery and a basis for learning. The weak knowledge boundaries between home and nursery were further evident, with many children proudly saying they had the books they were reading at nursery at home. These children were therefore already familiar with the academic knowledge they met in nursery and furthermore, practitioners encouraged and welcomed the knowledge children brought from home, using it to at times frame 'work play'. To some extent then, at $B B B$ what counted as learning was children practicing and demonstrating what they had already learned at home, whether it was from personal experiences or linguistic or cultural knowledge. There is limited disruption between the knowledge of the early year's setting and that derived from home. Practitioners used 'home knowledge' as the bases of their 'work and academic' play. Continuity between nursery and home knowledge and behavioural expectations meant that $B B B$ children arrived at nursery with a more developed understanding of social expectations and realised the value placed on 'academic play' over other forms of play. Their state of 'school readiness' was cemented at both nursery and home.

\section{CONCLUSION}


Our analyses address how play is structured, organised and enacted across EYE settings and what impact this has on young children's opportunity to meet the EYFS imagined ideal of being 'school ready'. In very many respects our findings resonate with those of Rogers and Lapping (2012) and Vincent and Ball (2007) confirming that education, even in the early years is subtly but profoundly classed. Different forms of play are promoted and encouraged based on assumptions made about the predispositions children bring to each setting and their ability (honed by virtue of their class) to recognise, display and perform appropriately those forms of play which are valued most.

Clear differences in relation to the structuring of play and learning are evident across the three EYE settings. However, practitioners' efforts to provide meaningful playful learning opportunities are not entirely of their own making. They are constricted by outside influences (Wood, 2007), namely the expectations of the EYFS, pressure from the primary school curriculum and from parents. Our data suggest that often parents either want their child made ready for school and are unconvinced that playful activities are effective in achieving this, or alternatively want practitioners to teach their child the basic skills of personal hygiene, behaviour etc. and again do not see play as an effective means of achieving this. At $L P$ and $L S$, practitioners concerned themselves primarily with children's social behaviour, spending considerable time encouraging children to behave appropriately through the use of regulative discourse. In contrast, at $B B B$, practitioners implicitly assumed children would share the values and behaviour patterns of the nursery, and therefore socialisation was not a central concern, rather practitioners used regulative and instructional discourse to ensure children were (cognitively) 'school' ready. Due to the continuity between nursery and home knowledge and behavioural expectations children at $B B B$ were able to display a more developed understanding of social expectations and endorse the value of 'academic play' over other forms of play. In contrast, children at $L S$ and $L P$ are socialised into ways of behaving appropriately in and for the moment rather than prospectively for 'school readiness'. Although given much the same opportunities to choose 'academic play' as children at $B B B$, in these two contexts children seemed either not to realise or reject its values. Consequently practitioners formed the expectation that they either could not or would not engage in this form of play; in effect essentialising their identities and differences. Social hierarchies both within and between settings were therefore produced, reflecting longstanding hierarchies within wider society (Sharp and Green, 1975).

Class relations affect both family and EYE setting, in that 'the ideologies of education are the ideologies of class' (predominately the middle class) (Bernstein, 1977). The invisible pedagogy which dominates EY settings, presupposes children will be in education for a long time and assumes that children arrive with certain predispositions and (elaborate codes) nurtured in their family context, which will orientate them towards the significance of relatively context independent meanings. In EYE settings, such pedagogy assumes that children will be able to recognise the value placed on academic play over other forms of play as a means of demonstrating 'school readiness'. The play forms described above begin to highlight how in the UK class regulates the structure of communication within both the family and, therefore, children's initial code orientation, and the EYE setting. Continuity between home and EYE privileges middle class behaviour codes, instructional discourse and 
culture. Political discourse which only addresses how, where and to whom resources are to be allocated in early year education is, therefore, likely to be of little value unless accompanied equally by critical understanding of how practitioners and children relate to each other once in such settings and the ideologies and orthodoxies which underpin their actions. 


\section{REFERENCES}

Ball, S. (2003). Class Strategies and the Education Market: The Middle Classes and Social Advantage. Oxon: RoutledgeFalmer.

Ball, S. (2010). New class inequalities in education: Why education policy may be looking in the wrong place! Education policy, civil society and social class. International Journal of Sociology and Social Policy, 30(3/4): 155-166.

Bernstein, B., (1973). A brief account of the theory of codes, in Class, Codes and Control, vol1, Routledge and Kegan Paul (revised edition-1974)

Bernstein, B., (1975). Class, Codes and Control Vol III: towards a theory of educational transmissions, London: Routledge and Kegan Paul.

Bernstein, B. (1977). Class, Codes and Control, Vol 3, Towards a Theory of Educational Transmissions, 2nd revised ed, London: Routledge and Kegan Paul

Bertram, T., and Pascal, C., (2002). Early Years Education: An International Perspective, Centre for Research in Early Childhood, Birmingham

Bodrova, E. and Leong, D.J. (2005), High quality preschool programs: what would Vygotsky say? Early Education and Development, 16 (4): 435-444

Bradbury, A., (2013). Education policy and the 'ideal learner': producing recognizable learner subjects through early years assessment, British Sociology of Education, 34 (1): 1-19

Broadhead, P., Howard, J., and Wood, E., (2013 ed.). Play and Learning in the Early Years, London: Sage

Brooker, L., (2010) 'Learning to play in a culutural context, in P.Broadhead, J., Howard and E., Wood (ed.) Play and Learning in the Early Years, London: Sage

DfE. 2003. Birth to Three Matters

www.education.gov.uk/publications/standard/publicationDetail/Page1/Birth (accessed October 2013)

DfE (2008) Early Years Foundation Stage

www.education.gov.uk/childrenandyoungpeople/earlylearningandchildcare/delivery/educatio n/a0068102/early-years-foundation-stage-eyfs (accessed 1/11/ 2011)

EYFS, (2014) Early Years Foundation Stage/Curriculum

https://www.gov.uk/government/uploads/system/uploads/attachment_data/file/335504/EYFS framework_from_1_September_2014_with_clarification_note.pdf (accessed 15/12/2015)

MacLure, Maggie, Jones, Liz , Holmes, Rachel and MacRae, Christina (2011) 'Becoming a problem:behaviour and reputation in the early years classroom', British Educational Research Journal, First published on: 15April 2011 (iFirst) 
McNaughton, G., (2005). Doing Foucault in Early Childhood Studies: Applying poststructural ideas. London: Routlegde

Mellou, E., (1994) Play Theories: A contemporary review, Early Child Development and Care, 102 (1): 91 - 100

Mellhuish,E., Romaniuk, H., Sammons, P., Sylva, K.,Siraj-Blatchford, I., and Taggart, B., (2004). The Effective Provision of Pre-School Education (EPPE) Project: Final Report, A Longitudinal Study Funded by the DfES 1997-2004, London: DfES/Institute of Education

Olssen, M., Codd, J. and O’Neill, A.-M (2004) Education policy: Globalization, citizenship and democracy, London: Sage

Plowden (1967) Children and their Primary Schools Report of the Central Advisory Council for Education (England) London: HMSO.

Rogers, S. and Lapping, C. (2012). Recontextualising 'Play' in Early Years Pedagogy: Competence, Performance and Excess in Policy and Practice, British Journal of Educational Studies 60 (3): 243-260

Sharp, R. and Green, A. (1975) Education and Social Control: A Study in Progressive Education, London: Routledge and Kegan Paul.

Siraj-Blatchford, I., Sylva, K., Muttock, S., Gilden, R. and Bell, D. (2002). Researching Effective Pedagogy in the Early Years, London, DfEE/Institute of Education: University of London

Siraj-Blatchford, I., and Sylva, K., (2004) Researching pedagogy in English preschools, British Educational Research Journal, 30 (5): 713-7

Takhvar, M., (1988) Play and theories of play. A review of literature, Early Child Development and Care, 39: 221-244.

Vincent, C., and Ball, S., (2007). 'Making up’ the middle-class child: Families, activities and class dispositions. Sociology 41(6): 1061-77

Viruru, R., (1997). 'Privileging child-centred, play-based instruction', in G. Cannella (ed.) Deconstrcuting Early Childhood Education, New York: Peter Lang

Wood, E., and Bennett, N., (1998) Teachers’ Theories of Play: Constructivist or Social Constructivist? Early Child Development and Care, 140 (1):17-30

Wood, E., and Attfield, J., (2005) Play learning and the early childhood curriculum, London: Paul Chapman 


\footnotetext{
' SES was based on parental occupation using the Office for National Statistics, NS-SEC occupationally based classification. Data on parental occupations was gathered from conversations with practitioners, children and in some cases the parents themselves

ii The SES score was calculated using the Office for National Statistics indices of deprivation measure. A score of 1 indicates the most deprived neighbourhood in England and a score of 32,482 indicates the least deprived neighbourhood in England

iii Within England and Wales, the government offers 15 hours per week free childcare to children ages 3years and since 2013, all two year olds from 'disadvantaged backgrounds' were to receive fifteen hours free education and this is to be extended to other families by Sept 2014 (EYFS, 2014)

${ }^{\text {iv }}$ Whilst acknowledging the idealised form of play as represented in the EYFS, academic research on early years (Broadbent, Howard and Woods, 2013) and literature addressing theories of play (Takhvar, 1988; Mellou, 1994; Wood and Bennett, 1998), our analyses by contrast documents how play actually materialises in early years settings. We delve beneath surface appearances to describe five forms of play which variously featured in the settings of this research.

${ }^{v}$ A learning journey is a celebration of a child's achievements and interests during the time they spend in a setting and shows the journey of a child's learning and development.

${ }^{\mathrm{vi}}$ Academically, referring to practitioners responsibility to fulfil the literacy and mathematics requirements of the EYFS $(2014$, p.8)
} 